Marquette University

e-Publications@Marquette

$1-1-2014$

\title{
"MacGyver-Meets-Dr. Ruth": Science Journalism and the Material Positioning of Dr. Carla Pugh
}

Lillian Campbell

Marquette University, lillian.campbell@marquette.edu

Accepted version. Women's Studies in Communication, Vol. 37, No. 1 (January 2014): 44-65. DOI. (C) 2014 Taylor \& Francis. Used with permission. 
"MacGyver-meets-Dr. Ruth":

Science Journalism and the Material Positioning of Dr. Carla Pugh

Lillian Campbell, University of Washington

\section{This is an Accepted Manuscript of an article published by Taylor \& Francis in Women's Studies in Communication on February 12, 2014 available online:} http://www.tandfonline.com/doi/full/10.1080/07491409.2013.867916

This article examines the rhetorical consequences of foregrounding female scientists' materials through an analysis of seven news articles on Dr. Carla Pugh, a surgeon who designs medical patient simulators. Journalists foreground Pugh's materials by positioning her as both "MacGyver," creatively assembling simulators from everyday objects, and "Dr. Ruth," willingly discussing intimate parts. These positions avoid focusing on Pugh's personal life or body, but still ultimately gender her and her work. The MacGyver position associates Pugh with gendered activities, objects, and spaces while undermining her affiliation with the technical aspects of design. Meanwhile, the Dr. Ruth position implies Pugh's knowledge comes from inherent bodily expertise, making certain scientific fields appear more natural for women.

Keywords: Female Scientists, Rhetoric, African American Women, Materiality, Health and Medicine 
Medical students arrive at a comprehensive understanding of a procedure not only by reading about it in a textbook or observing a doctor's techniques, but also by enacting it themselves. In her own account of her years in medical school, Dr. Carla Pugh, now a surgeon at the forefront of medical simulation design, shared her feelings of bewilderment: "If a doctor had his finger inside a man's rectum while performing a prostate exam, you could only see the back of his hand. You didn't know what he was touching on the patient" (Trice, 2010, p. 1). After years of frustration with her medical training, Pugh started building simulated body parts, beginning with an e-pelvis and then expanding to include rectal and breast models. These simulators offer medical students hands-on practice and feedback prior to their clinical placements. Pugh's work has received unexpected media coverage over the past decade, spurred in part by the unique materials she uses in simulator construction and the taboo body parts she builds. This essay examines seven news articles that describe the work of Dr. Pugh and considers the rhetorical consequences of foregrounding this female scientist's materials.

Dr. Pugh began doctoral work in education at Stanford in 2001 with the goal of developing a "web based educational program for surgeons." While there, she "found lower hanging fruit in simulation technology" and began to cooperate with fellow students to construct an e-pelvis that used sensory technology to measure and categorize touch (Pugh, 2012a, p. 1). Since expanding to design breast and rectal models, Pugh has received grants from the National Board of Medical Examiners as well as the National Institute of Health and in 2010 she was given the PECASE (Presidential Early Career Award for Scientists and Engineers) by President Obama for her simulation research. Her impact has already been far-reaching: "Currently, over one hundred medical and nursing schools are using one of her sensor enabled training tools for their students" (“Tenth Anniversary,” 2012, p. 5). 
From 2002, when her e-pelvis received its patent, to her most recent grants for simulated breast design, Pugh has been featured in Wired, the Chicago Sun Times, BBC News, The New York Times, The Chicago Tribune, The Seattle Times, and the Daily Mail. As an African American female scientist at the forefront of designing virtual simulators of intimate organs, Pugh provides an interesting case study for media coverage. Previous research has found that journalistic coverage of female scientists often relies on details about their looks, dress, and personal lives to garner reader interest: "These women are not only scientists (in their representation in the columns), they are also portrayed in their social or cultural roles as females with different personal traits" (Shachar, 2000, p. 354). My analysis of coverage of Pugh brings me to the same conclusion - that a woman scientist is differentially positioned because of her female role. However, media accounts of Pugh gender her in an unusual way: not by focusing on the details of her own materiality, but by focusing on the materiality of her simulators. In addition, Pugh's race is effaced in most accounts, countering typically tokenistic media coverage of members of under-represented groups (Shacar, 2000).

Seven news articles covering Pugh's research will provide an opportunity to understand the image of Pugh and her work that is being conveyed not by one journalist, but by multiple journalists who, deliberately or unconsciously, focus on Pugh's materials. Since descriptions of Pugh represent an anomaly for news coverage of female scientists, a rhetorical investigation of these articles can contribute to an understanding of how foregrounding the material can position a scientist and her work. A small corpus like this one lends itself well to a specific type of rhetorical analysis, a qualitative methodology that relies on close-reading of words and phrases to consider the ways that language can exert discursive force on the world, influencing power relationships and identities. This study takes a material-semiotic view of language, not asking 
whether it accurately reflects reality but instead how specific material articulations promote certain perspectives and silence others. Still, the small number of available texts on Pugh's research is a limitation of this study. While I offer this initial analysis as a case study of material positioning in coverage of a female scientist, future research might look at news coverage of a wider range of female scientists to consider material positioning on a broader scale.

One reporter, in referring to Pugh's “maverick MacGyver-meets-Dr. Ruth approach,” sets out two modes of characterization that prove to be representative of much of Pugh's news coverage (Morgan, 2008, p. F5). The "MacGyver" characterization is a reference to secret agent and scientist Angus MacGyver, star of a 1980's television show, who was famous for his ability to solve complex problems with everyday materials. In order to emphasize this side of Pugh's work, articles describe Pugh's scrappy creation of her simulators with objects like lentils and peanut butter, offering long lists of the everyday objects she uses. The "Dr. Ruth" characterization references Ruth Westheimer, an American sex therapist famous for her frank replies to caller questions on her radio and television show, Sexually Speaking, in the 1980's. This reference aligns Pugh with what Michelle Murphy (2004) calls "immodest witnessing," a characteristic of the self-help movement which called women to reclaim their bodies through visual and textual articulations of female anatomy (p. 118). Pugh is presented as a counterpoint to repressed male doctors, openly discussing and designing a range of intimate anatomical parts.

I will use these two characterizations to organize my examination of the material positioning of Pugh and her work. In doing so, this study extends previous research on journalistic coverage of female scientists with recognition of the burgeoning interest in the material and the body in rhetorical scholarship. I will argue that the newspapers' focus on the materiality of simulation technology results in alternate subject positions for Pugh but still 
ultimately genders her and her work in subtle ways. The emphasis on everyday objects calls attention to the grass-roots "maverick" nature of Pugh's work, positioning it against objectifying mainstream science and bridging the gap between scientific practice and everyday life by emphasizing the creativity and "craft" of simulator design. However, it also personalizes and domesticizes Pugh by locating her materials in the home and grocery store and at moments undermines her affiliations with the more technical aspects of design. Similarly, Pugh's confident relationship to intimate parts counters female stereotypes of modesty and shyness but its suggestions of inherent expertise for the female doctor in bodily matters also create limitations for women's engagement in other sciences. I will conclude by examining alternative accounts of Pugh's research to illuminate the possibilities and limitations of material positioning.

\section{Gendered Coverage in Science Journalism}

Scholars from a range of disciplines, including applied linguistics, rhetoric, science studies, and science communication, have taken an interest in scientific discourse. Beyond examining research articles or lab reports that circulate exclusively within scientific communities, these fields study scientific popularizations (the texts that mediate between the scientific community and various publics). Early work was often comparative, examining the rhetorical and linguistic differences between scientific texts and their popular translations. Fahnestock's “Accommodating Science” (1986) identified a shift from forensic to epideictic rhetoric in scientific popularizations, as well as a shift towards more certainty and an emphasis on the uniqueness of scientific claims (p. 278-79). Meanwhile, Myers' (1990) comparisons of internal rhetoric and popularizations of science found that the former create a narrative of science emphasizing the scientist's argument and the discipline's conceptual structure, while the latter 
use a narrative of nature employing a chronological account of the activity of scientific objects (p. 142). This focus on the objects obscures scientific materials and methods, creating an image of science as unmediated observation rather than organized practice.

While detailed and valuable, these early studies lacked a robust view of the public's role in scientific popularizations. Alan Gross (1996) called on scholars to move away from a deficit model of science-public interaction towards a contextual model in which public understanding is a joint creation of scientific and local knowledge (p. 6). In an overview of recent research, Condit et. al. (2012) found that most studies followed this call. Articles tended to focus on judgment, action, the public-science interaction, or theory-building (p. 387). Within the "judgment" focus, articles critiqued scientific popularizations for both "the failure to provide a faithful history" - limiting epistemic validity through reliance on myth or cultural narrative - as well as their alignment with "oppressive forces" such as colonialism and racism (p. 389). Along similar lines, my study identifies sexism at work in the material positioning of Dr. Pugh, which associates her with gendered spaces and objects and makes certain scientific fields appear more natural for women.

Within studies of scientific journalism, scholars have critiqued the "failure to provide a faithful history" of scientific practices by arguing that dominant cultural narratives about how science "works" deflect focus away from scientific methods and materials. In their study of the “Science Times" section of The New York Times, Fursich and Lester (1996) found that scientists in the stories were granted authority through "the dealing with 'real' data that is presumably free from any ideological and therefore subjective constraints" (p. 39). Thus, scientists gained credibility through portrayals that showed them accessing pristine data, rather than being led by individual investments or perspectives during the investigation process. Similarly, Hyland (2010) 
found that in order to establish closer proximity with their readers, popularizations focused on the scientists and future uses for their research rather than the methods: "Priority is given to the potential payoffs of the research and results, rather than the means of obtaining them" (p. 118). In addition, Curtis (1994) identified a detective story model in Science 80-86 that espouses a Baconian view of science: it progresses through induction and elimination. He argued that this narrative also obscures the methods and materials of scientific practice: "[Journalists] rarely, it is true, say what the methods are, beyond saying that science involves trial and error" (p. 430). In its specific focus on the materials and method of simulation design, coverage of Dr. Pugh diverges from this trend. This divergence can be explained in part by flexibility within the genre of science journalism.

Recent studies note how important it is for science journalists to work within the genre to bridge the gap between scientific practice and everyday life, while highlighting unexpected and exciting pieces of scientific research. In "Cultural Context and the Conventions of Science Journalism," Wilcox (2003) details the generic characteristics of science journalism, arguing that a similar format is used across a spectrum of scientific topics: "This format usually involves an opening statement about the possible research findings, a brief discussion of methods, statements from the researcher, other scientists... and discussion of the possible positive and negative social implications" (p. 236). As with any genre, science journalism is flexible and authors can adjust the degree of detail depending on the story at hand. These adjustments are made with the goal of garnering reader interest and details are included both to emphasize connections to readers' everyday experiences and to highlight entertaining or surprising aspects of the science at hand. In "Making Science Newsworthy," Stuart Allan (2008) argues about the importance of accessibility: "Particularly prized... are those events which illuminate the relevance of science to 
daily life, enabling the journalist to adopt a 'human angle' when constructing the news story" (p. 155). He also discusses "fascination value" as an important criterion for those who want to create stories that "spark amazement" (p. 155). As mentioned, studies have found that the desire to make science relatable and interesting to readers often results in a focus on the individual scientist over the scientific method. This desire also frequently brings about the removal of scientific collaborators from view.

In order to create an accessible portrait of a single scientist, journalists will often remove other scientists from the narrative and highlight a "lone researcher" despite the communal nature of the project (Charney, 2003). Those individuals are then presented differently, however, depending on their gender. When male scientists are described, their personalities often garner attention. Shachar's (2000) study of the "Science Times" sections of The New York Times for 1996 and 1997 found male scientists portrayed "as literally 'larger-than-life'...'prolific, opinionated, dynamic, charming' with 'restless mind and ambition,' their physiques are transformed accordingly" (p. 355). Meanwhile, Chimba and Kitzinger (2010) reported that when physical depictions of male scientists appeared in UK newspapers, they would align the men with "the 'Einstein/Darwin' stereotype or relate to the image of the (implicitly male) technological wizard or young 'geek' who has built up a fortune as a computer entrepreneur" ( $p$. 613). Thus, while focus on individual male scientists is common, these descriptions often reinforce their participation in the scientific endeavor-aligning them with familiar scientific identities. In contrast, researchers have found an unbalanced emphasis on feminine physical attributes and social positions outside of the lab when it comes to female scientists in the news.

The trend of characterizing female scientists by their appearance and social role has been evident in science reporting since the mid-twentieth century. In Selling Science, Dorothy Nelkin 
(1995) overviewed the depiction of female Nobel Prize winners in magazines and newspapers, including Science Digest, Time magazine, and The New York Times, finding a focus on their physical attributes and family roles. Dr. Maria Mayer, 1963 prize winner in Physics, was described as: "a tiny, shy, touchingly devoted wife and mother... her children were perfectly darling." Barbara McClintock, recipient of the 1983 Nobel Prize in medicine, was introduced as "well known for baking with black walnuts" (p. 19). In both instances, the scientists are characterized by roles outside of the lab, as mothers and cooks. Thus, their participation as women in society is foregrounded rather than their relationship to a scientific endeavor.

More recently, in "Spotlighting Women Scientists," Orly Shachar (2000) reviewed all "Science Times" sections of The New York Times for 1996 and 1997, finding that coverage of female scientists exemplified tokenistic practices. Specifically, Shachar found a focus on individual personality and style that overshadowed any scientific coverage: "These women are portrayed as individuals with their unusual interests, who are also scientists, while the male scientists are painted in their professional public position" (p. 356). Similarly, Mwenya Chimba and Jenny Kitzinger's study “Bimbo or Boffin?” (2010) also reported an emphasis on women's appearance and exceptional status in a sample of 12 national UK newspapers from January to June of 2006. Half of the profiles of women referred to their clothing, physique and/or hairstyle whereas this was only true for $21 \%$ of the profiles of men. Examples included: "She is impressive, an immaculately groomed woman of 70 , who could easily pass for 15 years younger" (Parry, The Times, 18 February 2006) and "this petite, feisty communicator" (Thorpe, Sunday Times, 18 June 2006) (p. 612). Attenborough (2011) summarizes it well in his discourse analysis of female scientists in the media when he says, "the mass media tend to present images of female scientists in which their status as 'female bodies' is foregrounded rather more than 
their status as 'scientific minds"' (p. 661).

Thus, coverage of Dr. Pugh diverges from typical scientific news coverage in both its focus on the materials and methods of her work and its silence about her physical and social attributes. However, the coverage still aligns with trends in the genre to target fascination and human interest through its emphasis on the quirky but familiar materials Pugh uses to design intimate body parts. To better understand how this material foregrounding can gender Pugh in different ways, I now turn to a rhetorical methodology for studying material positioning.

\section{A Rhetorical Framework for the Study of Material Positioning}

The social constructionist turn in the humanities widened rhetorical studies' sphere from an initial focus on persuasive discourse to a view that all language mediates between the material and the social. Jasinski (2001) explains that rhetorical studies examines language as a constructive force: "discourse exudes perspective, it exudes influence, and it exudes force. Discursive force is manifest through grammar and syntax, tropes and figures, structural patterns of arrangement or disposition, vocabulary and word choice, explicit argument” (p. xxi). This examination of "discursive force" through close textual analysis brought questions of culture, power, and identification to the forefront of rhetorical studies.

Central to the study of discursive force is a recursive view of the relationship between language and materiality. In "Bodysigns," Fleckenstein (2001) defines materiality as "the fluid potential of physical reality. It includes bodies, places, and performances_- 'enactments' of reality in particular places at specific times" (p. 762). She argues that this materiality is both shaping and shaped by "semiosis," the sign systems we use to pattern material reality. "Language evolves out of materiality, then reverberates back on that pool of potentiality, molding it to 
reflect an organized image that does not exist until so patterned. These material-semiotic systems comprise a complex network of feedback and feed forward loops, all of which create, disrupt, and re-create the other" (p. 771). In this material-semiotic view, questions of representational correctness have little relevance, but the rhetorician can ask instead whose interests are being promoted and what perspectives are being silenced by certain material articulations.

Scholars in science studies have long been interested in materiality as well, recognizing that scientists often determine cultural standards for how the physical world is articulated. Foucault's genealogies of medical, psychological, and sexual language, emphasize the relationship between discourse and technologies of power that shape what is speakable and knowable. For Foucault (1972) the "objects" of scientific knowledge, which include madness and health, are made possible by historically situated power relations: "The object [of discourse] does not await in limbo the order that will free it and enable it to become embodied in a visible and prolix objectivity; it does not preexist itself... it exists under the positive conditions of a complex group of relations" (p. 45). Objects come to exist in discursive practice through their inter-relationships - they are never isolated entities but richly networked possibilities.

However, it is not just objects that emerge through discursive practice for Foucault. Subject positions are also made possible through the complex network of power relations that underwrite statements. In The Archaeology of Knowledge, Foucault (1972) enumerates the qualities of a statement, which include a referential and associated field as well as "a subject (not the speaking consciousness, not the author of the formulation, but a position that may be filled in certain conditions by various individuals) and.... A materiality (which is not only the substance or support of the articulation, but a status, rules of transcription, possibilities of use and re-use)" (p. 115). He uses the example of a doctor to discuss how an individual can have a range of 
subject positions available in a given moment depending on their relations to the "object" (in this case the body) including the questioning subject, the listening subject, the seeing subject, and the observing subject (p. 52). Thus, material articulations and subject positions are products of discursive practices that have emerged out of systems of power, including patriarchy.

The close relationship between materiality and subjectivity in his research has made Foucault's theories compelling to feminist researchers: "The importance Foucault gives to the body is particularly appealing to feminists struggling to devise a materialist understanding of subjectivities" (Hennessey, 1993, p. 45). I use the term "material positioning" to describe articulations of materiality — in this case Pugh's materials - that position her as a certain kind of subject: MacGyver or Dr. Ruth. In particular, I am interested in how the subject positions made available to Pugh in these articulations are gendered, in less obvious ways than if Pugh's dress or body were being described.

In “Articulating Scientific Practice” John Lynch (2009) introduces a methodology for studying rhetorically how certain kinds of materiality are foregrounded through human articulations. For him, these patterns of foregrounding materialities emerge through societal practices: "specific practices of cultures, including scientific cultures, act as if materiality inheres in some objects (the physical) more so than others (the symbolic)" (p. 436). Ultimately, he calls for attention to language's role in our material organizations: "a critical perspective must also account for the articulations produced by human practices that distribute material elements" (p. 438). Proposing a methodology that links examinations of material articulations to gender analysis, Attenborough (2011) argues that media researchers can track patterns of representation across media coverage of a topic. In these patterns, foregrounding of specific materialities is central: "to foreground the body of a scientist once may be analytically insignificant; but to do so 
continuously, and in a particular way, is to give some idea of the image a journalist is deliberately seeking to achieve through his/her use of language" (p. 662). While I do not agree that material foregrounding is always necessarily "deliberate," I do align my analysis with Attenborough's examination of representational patterns to identify how a "particular way" of articulating the material furthers specific cultural values and perspectives.

My focus on how materials are foregrounded in the coverage of a female scientist and her work is specifically attentive to the media's articulations of scientific materiality. In coverage of Dr. Carla Pugh, I ask how certain material relations are emphasized rhetorically and what subject positions are made available to Dr. Pugh as a result of these material articulations. Admittedly, this rhetorical focus on the representation of Pugh's materials does not provide opportunities to consider the recursive relationship between scientific materials and discourse. Recent science scholarship, including the work of Bruno Latour and Karen Barad, calls for a focus on the active role of non-human entities, "actants," in discursive construction. Future work on the relationships between foregrounding of materials and gendered subjectivities might do more to account for the ways that the actants being described exert pressure back on the language available to the author. Specifically, ethnographic engagement with the journalists involved in writing about science could offer additional insight into the role of a scientist's materials as actants in the discourse of science journalism.

\section{The Material Positioning of Dr. Carla Pugh}

With frameworks for both gendered coverage in science journalism and material positioning in mind, I turn to my corpus, which includes seven news articles on Pugh's work. These articles were found using a LexisNexis search for key terms including "(Dr) (Carla) 
Pugh," "simulat(ion/or)," "breast," and "pelvis," supplemented by a search on ProQuest. Some of these articles share Associated Press text with articles from other publications. In those cases, because the content in both articles was the same, I analyzed the article with the most content. However, I included information about the other articles in Appendix 1. Articles that were analyzed are in bold; those that simply shared AP text are not bolded. The Seattle Times and The Daily Mail articles were released in the same week and share excerpts of Associated Press text but I analyzed both because the latter features a wider variety of images that are relevant to the analysis while the former has more textual content.

This search also identified two interviews with Pugh, one on NPR news and one on a local Chicago television station (WTTW). However, Pugh's own presentation of her work dominated these interviews, rather than the strategic telling of her story by a journalist. Thus, I chose to limit my focus to articles published in newspapers and magazines. Those have been the focus for previous studies on the journalistic coverage of female scientists and also better addressed my research question about the effects of the media's foregrounding of a scientist's materials. In the conclusion, I consider some of the differences between stories that made it into wide distribution and Pugh's own account.

In the case of Pugh's research, the emphasis on the quirky materials she uses to design intimate body parts fulfill both criteria for the genre of science journalism — human interest and entertainment—-simultaneously discussing items and parts that bridge the gap between scientific practice and everyday life but also repurposing those materials in a way that will "spark amazement” (Allen, 2008, ” p. 155). Thus, most descriptions of Pugh avoid mention of her race, gender, or appearance, focusing instead on her degrees and research. The Wired article jokingly emphasizes Pugh's numerous degrees by introducing her as, "Dr. Carla Pugh, a Stanford 
University research associate and general surgeon with more degrees than a thermometer" (Shreve, 2002, p. 1). Meanwhile, others focus on her current career as a surgeon, "Dr. Carla Pugh, a surgeon at the Northwestern University medical school..." (Morgan, 2008, p. F5) or researcher, “...a Chicago researcher who has a $\$ 1.8$ million federal grant to design the first physical test..." (Johnson, 2011, p. 1). In this case, a shift is occurring away from the female scientist's body. Without looking at the images that accompany these articles, a reader would never know that Pugh is African American.

One text, the Chicago Sun article written in 2007, was an outlier in both its emphasis on Pugh's race and background and its lack of discussion of her materials. The article's title reads, "She opened her own doors - By discovering a better way to train med students, Dr. Carla Pugh isn't just a great black doctor. She's a great doctor. Period," calling attention to Pugh's race while also arguing that Pugh's accomplishments are exceptional by any standard. The text discusses Pugh's placement in an exhibit on African American surgeons: "Her creation landed her a spot in a new exhibit honoring black academic surgeons for their contributions to medicine" (Rackl, 2007, p. 14). Interestingly, while The New York Times mentions this exhibit, it does not describe its focus on African American surgeons, saying instead that she "was honored last year at a celebration of pioneers in academic medicine at the National Library of Medicine that is currently touring the nation” (Morgan, 2008, p. F5). This effacing of Pugh's race seems particularly significant, since it leads to a less specific account of the exhibit.

Meanwhile, the Chicago Sun emphasizes Pugh's unique status as a female surgeon of color: "She grew up to become one of an estimated 386 black women surgeons in the country, according to Northwestern" (Rackl, 2007, p. 14). In addition, the article discusses the financial obstacles Pugh needed to overcome to earn her degrees: "Becoming a surgeon is never easy. It's 
especially difficult for a cash-strapped child of a single mother. 'Other kids at college are well fed and all they have to worry about is studying. I worried how will I pay my bills, will the lights go out, is the check going to bounce?' she said" (Rackl, 2007, p. 14). The article ends by positioning Pugh as a role model for under-represented students interested in medical education: “'I have a responsibility to encourage anyone who's under-represented,' she said. 'That's not just a black thing"' (Rackl, 2007, p. 14). This account of Pugh's work follows some of the more traditional patterns of rhetorical tokenism as described by Shachar (2000). These include "glorification of the exception" and "overcoming hardship in the course of the token life or career" (p. 350). Its focus is more on Pugh's embodiment as an African American female surgeon, than on her scientific materials. As I consider the emphasis on Pugh's materials that is apparent in the other articles, I will return to this more conventional coverage as a counterpoint.

\section{Macgyvering: Creative Simulator Design}

The "quirky" materials that are pieced together to form Pugh's simulators have the potential to provide a source of both entertainment and connection for newsreaders, meeting both criteria for the genre of science journalism. Thus, six of the seven articles delve into the details of Pugh's materials, offering extended lists of familiar products and photographs that focus on the lentils and foam she is repurposing to mimic tumors and cysts. This focus positions Pugh closer to creative art, emphasizing her innovative use of everyday materials to construct the simulators, rather than the technical science of design, which would give more attention to the production and interpretation of simulator data. At the same time, the material focus positions Pugh in spaces associated with feminine activities - the home, the grocery store, and a restaurant.

In dissecting Pugh's simulators down to their parts, the news articles list familiar items 
that are just as likely to be found in the home as in the lab. The New York Times article describes one model as "a scrotum using two wood balls linked by a rubber band (vas deferens) and suspended in an extra-large condom filled with oil and peanut butter” (Morgan, 2008, p. F5). While the "wood balls" may be slightly outside of a reader's everyday encounters, rubber bands, oil, and peanut butter are all likely in kitchen cabinets. The $B B C$ article adds dolls to the list: "She also buys baby dolls for delivery models, squishy balls are used to represent ovarian masses and harder wooden balls for ovarian cancers" (Elliott, 2002, p. 1). Some lists even get specific with familiar brands. That same The New York Times mentions "Play-doh" in another list, while a Wired article includes "Saran Wrap" in its enumeration. These lists position Pugh closer to non-scientific readers, providing numerous opportunities for connection to Pugh's project.

The everyday nature of Pugh's materials is also emphasized in two images featured in the Daily Mail article. The first image shows a hand holding a somewhat transparent yellow cutout that is covered with lentils, one of three in the scene. On the left-hand side of the frame is a large plastic bag filled with plastic pieces and in the background are three Tupperware containers filled with assorted craft goods: pom-poms and foam are visible. The caption on the first photo reads: "Lumps: The fake breasts are filled with 'tumours' and lumps made from lentils, beans and clay." The second photo shows a person's torso and hands holding pieces of foam and a pom-pom. In the background are the Tupperware containers. The second caption reads, "Despite a $\$ 1.8$ million federal grant to develop the prosthetic breasts, doctors find the most realistic way to recreate tumors is with household products" (Neville, 2011, p. 1).

Most evident in both photos is a focus on materials instead of Pugh. The hands in the photo are the only evidence of the scientist and instead the familiar-looking objects are foregrounded. Notably, the scenes look like they could be set at a kitchen counter as easily as in 
a lab-room. The table is a simple slate color and the body in the photo is dressed in a black suit, rather than a lab coat. The use of plastic bags and Tupperware to organize materials again evokes a kitchen or craft room more than it does a laboratory. In both captions, the simulated part is introduced first: "lumps," "fake breasts," "prosthetic breasts," and "tumours." Meanwhile, the materials used for design follow: "lentils, beans, and clay" and "household products." Captions on photos strategically direct reader attention based on anticipated viewer response. The captions assume that the objects in the scene are already comprehensible to viewers but that they need guidance in understanding the relationship between the materials and the simulators. Thus, the familiarity of Pugh's materials and her positioning close to everyday experiences is evident in the captions of as well.

Similarly, the text of the Daily Mail article dissects Pugh's simulators down to their parts: "some of the 'fake tumours' are made from nothing more than beans glued together, glass beads and hardened clay. Lentils embedded in rubber mimic the feel of fibrocystic breast changes" (Neville, 2011, p. 1). The variety of "crafty" materials in this list - bean, beads, clay, and lentils - reinforces the craft room feel of the photographs featuring Tupperware containers filled with materials. In addition, the article quotes Pugh about her experience identifying materials in her everyday surroundings: "Any material I encounter on a daily basis is fair game to help me build a patient" (Neville, 2011, p. 1). The descriptions and quotation work alongside the photographs to emphasize the everyday nature of Pugh's activities: the materials that make up her work likely look very similar to those of a non-scientific reader.

The Seattle Times article, which shares much of the text with The Daily Mail article, adds a sentence that positions Pugh in certain everyday locations that help her to identify materials: "More than once she's been at a supermarket, restaurant or clothing store, spotted an object and 
thought, 'Oh, I could use that!'” (Johnson, 2011, p. 1). Notable in this excerpt is the three locations where the author places Pugh's materials - the supermarket, restaurant, or clothing store - all spaces outside of the laboratory that evoke cooking, dating, and shopping: feminized activities. Thus, even without ever addressing Pugh's marital status or favorite recipe, the article still personalizes and domesticizes Pugh by relating her materials to her private life.

The human connection to Pugh's work that is achieved through a focus on familiar materials also helps to distance her work from an alienating scientific elite. Typical science popularizations, which emphasize the pristine nature of scientific methods by avoiding a discussion of process, have the potential to reinforce this elitist positioning of scientists. Scientists are presented at a distance from readers, as having unmediated access to natural forces (Curtis, 1994; Fursich and Lester, 1996; Hyland, 2010). In contrast, material articulations position Pugh close to the home, reducing the distance between scientific practice and everyday experience. In addition, the articles portray Pugh's material work in process, responding on the ground with changes as they are needed.

For example, The Seattle Times article concludes with an interaction between Pugh and her research assistant, Jon Salud: "Foam rubber alone wasn't convincing doctors during the last trial that it was a fibroadenoma, another noncancerous condition, so Pugh directs research assistant Jon Salud to make a change. 'This is what I want next, Jon,' she tells him. 'I want lentils in this"' (Johnson, 2011, p. 1). Here, Pugh is shown innovating with local materials to solve local problems. She is positioned on the ground in her research, modifying the models according to direct feedback and using practical solutions. At the same time, the excerpt highlights Pugh's creativity and innovation in the quirky last line: "I want lentils in this." Thus, 
the MacGyver position offers an image of Pugh as a grassroots innovator, distancing her from a public conception of the scientific elite that could alienate readers.

At the same time, however, the lists of everyday materials are also less likely to lead to thorough explanations of the computer and sensor technology that accompanies Pugh's work. The Chicago Tribune describes the mechanism of Pugh's simulators saying, "When a student practices performing an internal exam, lights, bells and whistles go off to show the instructor when the student has touched the correct area and applied the proper amount of pressure" (Trice, 2010, p. 1). This description uses conversational language, "lights, bells, and whistles," that makes the simulators' operations seem obvious and the results easy to interpret. Meanwhile, the Wired article emphasizes the interface's images of intimate parts rather than its functionality: "They wrote software for the computer interface, which looks like it belongs on the set of a lowbudget, pornographic sci-fi movie" (Shreve, 2002, p. 1). In highlighting the oddly sexual nature of the computer interface, the technical details about what information is being displayed and how users are interpreting that data are obscured.

Even when the articles do address the simulators' technical design, their explanations focus on how a student's pressure on sensors in the simulator is registered by the computer:

- "software on an attached computer shows just what's being touched, how hard and how thoroughly" (Shreve, 2002, p. 1)

- "The newest models are fitted with sensors that can give students feedback on whether they're doing an exam properly or not" (Johnson, 2011, p. 1)

- "There are paper-thin sensors inside [each model] to measure a student's touch and send individual readings to an attached computer monitor" (Elliott, 2002, p. 1) 
None of the articles addresses the question of how sensor data is translated into comprehensible feedback to instructor or student. Pugh provides the answer in a speech: data is translated into color-coded graphs that show which anatomical parts are being touched and with what degree of pressure. By avoiding an explanation of the link between the simulator, computer, and data that is accessible to the researcher, the effect is two-fold. It obscures the science at hand, mystifying the process that allows the machines to do their work. At the same time, it distances Pugh from the technical work of her designs, affiliating her with the more creative side of production.

This effect is heightened by descriptions of Pugh that attribute the technology of her designs to other sources. Articles credit her collaborators, as in the example, "With the help of a computer-savvy classmate..." (Shreve, 2002, p. 1). They also credit the environment at Stanford for her technological successes. For example one passage reads, "Blessed with an education that took her through Stanford University in the tech-frenzied late 1990s..." (Morgan, 2008, p. F5). Thus, by attributing technical design to other individuals or the environment, the articles avoid crediting Pugh for the technologically complex computer systems that allow the simulators to measure pressure and touch. This perpetuates notions that certain kinds of science- - hands-on, creative design - are more accessible to women than others, a notion that will return in Pugh's Dr. Ruth positioning as well.

Overall, enumeration of the parts of her simulators emphasizes human connection by discussing Pugh's work with familiar materials, positioning her in closer proximity to daily life. At the same time she is positioned as a resourceful grass-roots innovator, drawing on everyday objects to produce strange and effective designs that are counter to an elitist current of mainstream science. However, the location of Pugh's materials in grocery stores, restaurants, and shops personalizes and domesticizes Pugh like descriptions of clothing and home life did in 
previous descriptions of female scientists. Meanwhile, the parts of her sensor/computer set-up are given much less discussion and the authors provide fewer details about her experiments to determine validity and accuracy. This works to undermine Pugh's technological expertise and to mystify the science behind her simulators for readers. Thus, the details of Pugh's process and her technical engagement with the simulators falls out of view. Once again the bodies are privileged over the scientific mind, though this time the bodies are made out of lentils and peanut butter.

\section{Dr. Ruthing: Engaging with Private Parts}

Not only is Pugh positioned as a grassroots innovator crafting simulators from familiar household materials, but her creative materials are also used to construct intimate parts with wide variations that position her as confident and willing to speak openly about the body. At the same time, some articles re-affirm her modesty, suggesting her confidence with intimate parts is only appropriate in the context of scientific study. Pugh's bold relationship to her materials is simultaneously contrasted with the more bashful relationship between student doctors and bodies, both of the real and simulated variety. By figuring Pugh as the doctor who is unafraid to talk about and engage with sensitive parts, the authors dissociate her from her squeamish and prudish medical students and colleagues. Still, the articles suggest that this confident relationship is the result of inherent expertise, thereby demarcating some scientific fields as more appropriate for women than others.

In their willingness to observe and articulate their individual bodies, feminists that participated in the women's health movement in the 1970's called attention to the variations that exist between "normal" bodies. Linking this focus on variation to her concept of "immodest witnessing," Murphy explains: "their intimate examination of reproductive variation was not 
primarily a search for ill health, but rather an effort to remove reproduction from its association with pathology, revaluing it in terms of, not despite of, individual biological variation (2004, p. 134). Similarly, Pugh's explicit descriptions of the body are often focused on calling attention to variation and difference, expanding the range of "normalcy" for doctors. The Chicago Tribune article discusses Pugh's work to include an extensive variety of breast models in doctor training: "And because breasts come in many different sizes and shapes — despite the fact that medical school training dummies mostly have perky, size 36 B breasts — Pugh plans to create more than a hundred sizes of simulated breasts for doctors to palpate" (Trice, 2010, p. 1).

In addition to calling attention to variation, speaking the body was a means for feminists to reclaim intimate parts that had become dirty words in public discourse. Karlyn Kohrs Campbell (1973) explains in “The Rhetoric of Women's Liberation: An Oxymoron” that "women's liberation rhetoric is characterized by the use of confrontative, non-adjustive strategies [that] violate the norms of decorum, morality, and 'femininity' of the women addressed" (p. 204). In creating and describing intimate simulation parts, Pugh is in some ways aligned with these goals in that she counters feminine stereotypes of modesty, shyness, and discreetness.

The $B B C$ News article features two quotations from Pugh exemplifying this willingness to speak the body in the interest of improving student experience. In one quotation, Pugh describes in explicit detail the problems with current models: "One model that was available for teaching the students had the rectum in the wrong place, in another the prostate was in the wrong position. The penises that were available were made of styrofoam and they were all the same" (Elliott, 2002, p. 1). Here she openly discusses the rectum, prostate and penis, while in a later quote she describes the process of going into porn shops to request parts: "I had to go into porn shops and ask for lots of penises, all sizes, erect and not erect, circumcised and non-circumcised. 
I was met with gales of laughter in the shops" (Elliott, 2002, p. 1). Both quotations show Pugh as unabashedly discussing the body, even when her confidence upends the expectations of workers in a sex shop. At the same time, they emphasize her commitment to faithfully representing the wide variety that exists even among healthy bodies.

The $B B C$ News article also locates Pugh in the porn shop, again suggesting an empowered relationship to intimate parts. The article, titled "The XXX-rated med school teacher," begins by describing Pugh's ventures to sex shops: "Dr Carla Pugh makes an unusual shopping trip at the start of every academic year as she prepares teaching materials for her medical students - to porn emporia and toy shops" (Elliott, 2002, p. 1). As the confident buyer of a full range of erect penises, Pugh is again presented as someone who is comfortable speaking publicly about intimate parts. The porn industry's notorious affiliation with the objectification and commodification of female bodies calls into question the extent to which Pugh's placement in a porn shop can be seen as "empowerment." Still, this positioning contradicts typical affiliations between femininity and modesty.

In fact, Pugh's open relationship to intimate parts poses enough of an affront to traditional gender expectations that the news articles find numerous ways to moderate the extent of Pugh's taboo actions. After describing a scene of Pugh shopping for simulation parts at novelty shops and then welding tubing onto penises to simulate a foreskin, The New York Times article follows by saying, "Her models are perhaps not as polished as some simulators on the market, but they are realistic enough that she hides them from male friends" (Morgan, 2008, p. F5). Here, Pugh's modesty in the face of her "male friends," suggests that her empowered relationship to intimate parts is justified by the science. In situations outside of the laboratory, 
the articles highlight how she avoids offending others by hiding her confident relationship to intimate parts, imposing boundaries on when and where she can challenge gender norms.

Even within the laboratory, the articles emphasize Pugh's modesty whenever the intimate parts are not being used for scientific purposes: "The current prototype, a disembodied plastic breast hooked by wires to a computer, modestly wears a blue cloth covering when not being examined. 'Because it's a human being,' Pugh explains when asked about the covering. 'She's sitting there on the table with her breast exposed, so when we're not examining her we cover her. It's a habit that we've formed"' (Johnson, 2011, p. 1). Thus, the articles impose a limit on Pugh's "Dr. Ruth" persona — she can be portrayed as confident and open about body parts whenever scientific examinations are underway, but otherwise she treat the parts modestly. In these moments the articles actively counter Pugh's Dr. Ruth positioning, justifying that role in the name of science, and moderating it as soon as science is not at stake. This is evidence of the limitations of material positioning as a means for challenging sexist cultural views.

While articles find ways to regulate the extent of Pugh's taboo behavior, they still present her in stark contrast to bashful student doctors and colleagues. The New York Times article features an image of Pugh discussing her simulators with a fellow doctor whose hand is inside a pelvic simulator. The caption reads, "Dr. Pugh, right, discusses one of her model body parts with Dr. Katherine Blossfield" (Morgan, 2008, p. F5). Both women appear to be actively participating in the conversation and Pugh is mid-sentence holding up her hands in a circular shape while Blossfield looks on. The caption and the image reinforce Pugh's relationship to intimate body parts as one of openness and confidence - she is shown actively speaking about the body.

Another photo that begins that article, however, conveys a different relationship between doctor and body. It shows the side profile of a male doctor in a white lab coat looking forward 
toward either a computerized avatar head and torso or the computer in the scene that is positioned next to her head. His hands are inside a truncated pelvic model. The patient is likely female, though her hair is pulled away from her face and her torso is not clearly feminized. The avatar patient looks uncomfortable: her arms are folded across her chest and her head is turned away from the doctor's gaze. The caption reads, "LIFELIKE, ALMOST: A pelvic exam simulator combines a three-dimensional model with a computerized avatar" (Morgan, 2008, p. F5). In this instance, the patient is portrayed as on edge and the doctor is not shown interacting with the avatar. Overall, this image does suggest an increase in doctor confidence, but also discomfort and a lack of connection in doctor-patient interaction. The text of the article interacts with the photo by elaborating on the image of the squeamish and prudish doctor who needs simulators to overcome his or her discomfort with the body, contrasting this with Pugh's confidence in discussing the body.

The title of The New York Times article captures this contrast succinctly: "Building Organs Even the Prudish Can Handle." Here, the simulators are introduced as an intermediary step for "prudish" student doctors to start gaining comfort with intimate parts. The article jokingly contrasts the complexity of medical work with doctors' inabilities to overcome embarrassment: "When it comes to surgery, the hardest part of the human body to remove turns out to be the fig leaf" (Morgan, 2008, p. F5). In presenting an image of the squeamish doctor, The New York Times article has to counter public perceptions of the doctor as unaffected witness. To do so, it often attempts to bridge doctor training experiences with reader's everyday experiences, upending distinctions between doctors and "normal people" with relish. The article links doctor's insecurities to those of the general public, "Medical schools have a dirty secret: they can be just as puritan as the rest of us" (Morgan, 2008, p. F5). It even goes as far in the 
conclusion as to identify doctors' insecurities with a larger American disposition, ending with a quote from sex columnist Dan Savage: "That's America... Canada got the French. Australia got the convicts. We got the Puritans and we never got over it"' (Morgan, 2008, p. F5). Meanwhile, Pugh's quotes reinforce shared feelings of discomfort and embarrassment in the initial encounter between patient and student doctor saying: "It's not like med school students are gifted to the degree that they can touch a stranger's genitals and look them in the eye and have a calm conversation without feeling weird about it"' (Morgan, 2008, p. F5). This description of a typical medical room encounter calls the reader into the doctor's perspective and evokes the feelings of embarrassment that would come from such an encounter.

The Chicago Tribune article also relies on quotations from Pugh about medical students' trepidations to emphasize the "prudish" nature of medical students. Pugh describes insecurities as occasionally interfering with students' abilities to interact with her simulators: "Pugh said medical students sometimes are reluctant to touch the simulators" (Trice, 2010, p. 1). Pugh explains these anxieties by linking experiences of medical students with the discomfort of average students. In doing so, her quotations again work to undermine distinctions between doctors and readers: "Medical students go from dorm room learning to having to look serious in front of a naked person,' Pugh said" (Trice, 2010, p. 1). The reference to "dorm rooms" humanizes medical students by placing them in a situation that is typically associated with youth and immaturity. Overall, in revealing an awkward aspect of medical education, the articles are also creating opportunities for empathetic connection between reader and doctor, asking readers to humanize their doctors and recognize shared insecurities about bodily encounters.

At the same time, Pugh's bold relationship to body parts and dissociation from prudish doctors removes her from this potential for reader connection, suggesting instead an inherent 
bodily confidence and knowledge. Since the prudish doctors are often figured as male, this contributes to perpetuating assumptions about innate gendered dispositions for certain fields. By describing Pugh's comfort with intimate parts as natural, her confident relationship to the body also has the potential to reinforce ideas that some scientific fields, such as human anatomy, are more appropriate for women than others.

Four of the articles figure Pugh's interest in designing intimate body parts as inherent or predetermined. The New York Times article transitions from the observation that, "Many students become doctors never having learned the nuances of checking for cancerous lumps in larger, smaller, flatter, fuller or droopier breasts" to Pugh's intervention in the problem, without any explanation of her own experiences as a student: "So Dr. Carla Pugh, a surgeon at the Northwestern University medical school, takes matters into her own hands. She builds fake breasts ..." (Morgan, 2008, p. F5). Meanwhile, The Wired article does address Pugh's choice to intervene but suggests that the decision was an "immediate" thought that came to Pugh when she first encountered simulation technology at Stanford: "When I learned about the possibilities of using sensors and creating a computer interface, I immediately thought to do the breasts, the pelvis or the prostate. I ended up doing the pelvis because that's what materials I had readily available to me,' explains Pugh" (Shreve, 2002, p. 1).

The Chicago Tribune attributes Pugh's designs to her own frustration in medical school, quoting her description of watching her professors perform procedures and not being able to understand their technique (Trice, 2010, p. 1). Even that article, however, begins with a description of Pugh playing with a "Baby Alive" doll as a child, suggesting that her curiosity in and comfort with the body is a long-standing characteristic: "whenever Pugh fed the doll, she immediately would press on its abdomen, encouraging nature to take its course so she could 
unlock the mystery of digestion" (Trice, 2010, p. 1). Similarly, the BBC News article describes Pugh's play with her childhood dolls as evidence of inherent medical expertise: "Dr. Pugh began performing 'surgery' on her dolls as a child, transplanting eyes and limbs with a sewing kit borrowed from her mother" (Elliott, 2002, p. 1). Here, Pugh's early interest in surgery is also feminized through alignment with her mother's domestic pursuits, her sewing kit, and her dolls.

In contrast, the Chicago Sun Times foregrounds Pugh's feelings of confusion more prominently, beginning with three haunting questions: "Dr. Carla Pugh remembers how nervous she felt about performing her first pelvic exam in medical school. Would she hurt the patient? Would her fingers be able to find the woman's cervix? Feel her uterus?" (Rackl, 2007, p. 14). This raw portrayal of Pugh's discomfort is aligned with the text's focus on "overcoming adversity," so it makes sense in its overall narrative to begin by emphasizing her struggles in medical school. Interestingly, this article also discusses Pugh's childhood as evidence of an inherent medical expertise, but rather than affiliating her with feminine toys, it positions her working with medical tools at a young age: "Her mother gave her a stethoscope when she was 6 . She'd bring it to the grocery store, holding it up to customers' ankles in hopes of hearing a heartbeat" (Rackl, 2007, p. 14). This example suggests inherent expertise but avoids linking Pugh's gender to certain kinds of careers. She is shown engaging with the technical tools of the discipline at a young age, rather than feminine playthings that are then linked to surgery.

Thus, with the exception of the Chicago Sun Times article, news coverage articulates a confident "Dr. Ruth" position for Pugh in relation to her simulated intimate parts, dissociating her from the insecure or prudish male student doctors. In speaking and constructing private parts, she is aligned with feminist movements to reclaim the female body but her openness and confidence are also regulated in contexts outside of the lab. At the same time, Pugh's confidence 
is often featured as innate, emerging from embodied knowledge and suggesting that women might have inherent expertise for certain scientific fields, like human anatomy.

\section{Conclusion}

Overall, Pugh's material positioning works to navigate the challenges of science journalism while at times avoiding and at other times reaffirming norms of gender representation. Articles about Pugh position her as creatively repurposing everyday materials and confidently discussing intimate parts, but in doing so they personalize and domesticize Pugh's work and suggest inherent bodily expertise. These news stories differ from Pugh's own account of her research, which addresses her role in interpreting data from the simulators as well as her frustrations in medical school with her lack of anatomical knowledge. While admittedly written for a more scientific audience, Pugh's account demonstrates alternative ways to represent her work that could be taken up in scientific popularizations as well. After considering these alternative representations, this paper will conclude with questions for further research on the gendered impact of material positioning.

While Allan (2008) argues that all science journalism attempts to garner "human interest," female scientists are often humanized through emphasis on their social lives and dress. In contrast, coverage of Pugh bridges the gap between scientific practice and reader experience by positioning Pugh in relation to familiar, everyday items like lentils and peanut butter. From a feminist perspective, this material positioning has several advantages. Rather than isolating Pugh's work as a scientist from her personal experiences and focusing on the personal, this coverage suggests that her scientific work is a part of her identity. In this way, it depicts Pugh as a creative and unique individual within the lab. This differs from coverage of male scientists 
aligning them with familiar scientific identities because it does not rely on Pugh's physical traits or personality to place her within a scientific endeavor (Chimba and Kitzinger, 2010, p. 613). Instead, it is her materials that both differentiate her as an individual and align her with scientific practice. At the same time, the focus on Pugh's materials positions her as a grassroots innovator, responding readily to the needs of the lab. This distances her from an elitist positioning of the scientist as well, creating the potential for reader identification and connection. And yet, the foregrounding of Pugh's materials still genders her in specific ways, associating her with gendered activities, objects, and spaces and aligning her with creative rather than technical aspects of simulation design.

On the other hand, Pugh's positioning as Dr. Ruth puts her into a confident relationship to intimate parts, countering common portrayals of women as shy or bashful. In some ways, Pugh's willingness to discuss and create models of these private parts aligns her with the immodest witnessing of the women's health movement that worked to both visually and verbally reclaim the female body through individualized encounters. In "The Rhetoric of Women's Liberation," Campbell discusses the wide range of confrontational texts produced by feminists in the 70's: "Essays on frigidity and orgasm, essays by prostitutes and lesbians, personal accounts of promiscuity and masochism...'violate the reality structure' by close analysis of tabooed subjects" (p. 204). While Pugh's brazen discussions may not seem in the same revolutionary realm as these texts, her willingness to speak graphically about intimate parts in the interest of calling medical attention to physical variation is very much in line with their efforts. The Dr. Ruth persona positions Pugh in opposition to her reserved male colleagues, speaking about the individual body in a community prone to reticence. She is regularly quoted speaking about the body in detail as she describes her simulators, specifically calling attention to the minutia of 
physical variation. This resonates with the work of feminists as well, whose "schooled attention to slight variations in anatomical detail produced a topography through which the feminist selfhelp movement remapped healthfulness" (Murphy, 2004, p. 130).

In this way, Pugh's materials position her in the porn shop, a strong contrast to accounts that placed female scientists at home with their children. This location is such an affront to gendered cultural norms, however, that a number of the articles regulate Pugh's immodesty. Again, this is evidence of the limitations of material positioning as a means for challenging sexist cultural views. These articles demarcate Pugh's material positioning as Dr. Ruth, restricting that position to her scientific work, in order to align her coverage more closely with cultural norms.

In addition, Pugh's material positioning as both MacGyver and Dr. Ruth presents her affinity for creative design and comfort with intimate parts as intrinsic and gendered traits. This implies that she is naturally suited for a career in surgery and simulation design, but also distances her from technological work and other scientific fields. One problematic result of presenting a scientist's relationship to their materials as "natural," then, is this suggestion of inherent expertise. An alternative account of her research that does not rely on a narrative of inherent expertise can be found in Pugh's speech. On June 22, 2012 she delivered an overview of her research and design at The National Institute of Biomedical Imaging and Bioengineering (NIBIB) $10^{\text {th }}$ Anniversary symposium and showcase in Bethesda, MD. Her speech, entitled "Use of Sensors and Simulation Technology to Quantify Clinical Palpation" begins with her own experiences as a student watching residents perform surgeries, overviews her initial work at Stanford, and moves into a discussion of her data from pelvic, rectal, and breast exams on her simulators. In both its discussion of Pugh's relationship to simulator data and of her early experiences in medical school, the speech offers alternatives to a narrative of natural affinity. 
First, accounts of Pugh's material work focus on her innovative repurposing of kitchen items rather than her software design and interpretation of data. In this way, they foreground her creative work with her materials while deemphasizing her technical know-how. None of the articles offer a thorough explanation of the link between the simulator, computer, and data and some even make this connection seem simplistic or transparent. In contrast, during her speech at NIBIB Pugh uses graphs derived from sensors in the simulators to show the audience how data can be interpreted to make conclusions about physician effectiveness.

Pugh discusses the graphs that map data from sensors on the simulators into comprehensible patterns saying, "All of the procedures we do have a signature - show me any graph and I can pretty much know whether it was a prostate exam or an intubation or something because they all have a signature" (Pugh, 2012b). Not one of the articles mentions graphs as an analytic tool, even though a few of the images in the articles show computers screens displaying sensor data. Including a discussion of not only the design of Pugh's simulators but also the graphs that Pugh reads as signatures from the sensor data would have opened up the scientific complexity of her research rather than obscuring it. This would have presented Pugh as someone close to both the technical aspects of her research, as well as the creative design. In addition, those graph signatures are easily relatable to familiar materials in reader's experiences, like heart monitor graphs. Using an analogy to explain the process of reading sensor data could clarify the science for readers, rather than mystifying the process.

Thus, while a focus on materials might seem to inherently counter previous findings that scientific popularizations deflect method (Curtis, 1994; Fursich and Lester, 1996; Hyland, 2010), my analysis has found that methods can still be deflected even as scientific materials receive attention. One question investigators might ask as they continue to consider discussions of 
materiality in public science communication then, is: how does material positioning open up or obscure a reader's access to the scientific practice?

Second, in presenting Pugh as comfortably speaking and building intimate body parts, articles often emphasized this as a natural relationship for her, one that could be traced back to early interest in the body. Pugh's feelings of discomfort and confusion with anatomy in medical school go largely unmentioned, while her childhood encounters with a "Baby Alive" doll receive the focus alongside discussions of her "immediate" recognition of possible solutions in the lab. In contrast, in her speech at the NIBIB symposium, Pugh (2012b) is clear about establishing a causal link between her own frustrations with surgical education and her decision to study simulation's role in medical education: "as I watched [my professors] perform surgeries and physical examinations I would find myself wishing and hoping that somehow, their level of discernment could magically be transferred to my fingertips but obviously that was not possible" (Pugh, 2012b). Pugh humorously allows her audience to experience her state of confusion as a student by projecting an image of the back of a surgeon's hand, saying, "This is what I saw for the entirety of the procedure." She goes on to describe the senior resident's confusion when she requested to "feel what you're feeling." Here, the only inherent characteristics Pugh attributes to herself are curiosity and a desire for more encounters with parts that were not immediately visible during surgery. She presents herself as more bold than the typical medical student, but not necessarily more confident about her abilities or comfortable with patient bodies. This is in sharp contrast to the articles' suggestions of inherent expertise and natural affinity for surgery.

Creating space to share experiences, specifically those of frustration and confusion, was a foundation of the feminist health movement. Murphy explains how "The central epistemological principle of feminist self-help, as with radical feminism more generally, was that all knowledge 
production should begin with women's experiences... At work in statements such as 'I saw this,' 'I was there,' 'I felt that' uttered at self-help meetings was the assertion of an epistemic privilege gained from the immediacy of speaking about one's self' (2004, p. 118). Thus, providing space for Pugh's initial experiences with the body in medical training or featuring female doctors that show trepidation in their material and bodily encounters would have been more loyal to these feminist practices.

The Chicago Sun Times article indicates that this narrative of overcoming tribulations is in danger of aligning with tokenistic presentations of female scientists that focus on overcoming adversity. However, a focus on Pugh's materials does not preclude a discussion of her anxieties. Sharing her less successful encounters with body parts might have helped to avoid the more problematic conclusions about embodied expertise that result from portraying Pugh's Dr. Ruth figuration as inherent. This would open up medical study to readers who might not feel immediately comfortable with the body. Another question for researchers interested in the foregrounding of materiality in scientific coverage then, is: how and when are material-human relations depicted as natural versus learned, and what are the consequences of that presentation?

Overall, coverage of Pugh's research shows the potential for public accounts of scientific materials to challenge conventional portrayals of female scientists in the news. The emphasis on materiality in Pugh's coverage positions her as both relatable and confident and yet, it obscures the more technical aspects of her work and suggests a natural affinity for certain sciences. Pugh's report on her research offers more fruitful articulations of scientific materials that could be taken up in science popularizations as well. Additional investigations of how materials are mobilized in public science accounts could provide openings to further understand the relationship between the public communication of science, gendered positioning of female scientists, and the material. 


\section{Works Cited}

Allan, S. (2008). Making science newsworthy: Exploring the conventions of science journalism. In R. Holliman, E. Whitelegg, E. Scanlon, S. Smidt, and J. Thomas (Ed.), Investigating science communication in the information age: Implications for public engagement and popular media (pp. 149-165). Oxford, England: Oxford University Press.

Attenborough, F. (2011). Complicating the sexualization thesis: The media, gender, and 'scicandy.' Discourse \& Society, 22, 659-676.

Campbell, K. K. (1973). The rhetoric of women's liberation: An oxymoron. Quarterly Journal of Speech, 59, 74-86.

Charney, D. (2003 July). Lone geniuses in popular science: The devaluation of scientific consensus. Written Communication, 20(3), 215-241.

Chimba, M, \& Kitzinger, J. (2010). Bimbo or boffin? Women in science: An analysis of media representations and how female scientists negotiate cultural contradictions. Public Understanding of Science,19(5), 609-624.

Clark-Flory, T. (2008, Feb. 12). Round-up: Life-saving fake breasts and more. Salon. Retrieved from http://www.salon.com.

Condit, C. M., Lynch, J., Winderman, E. (2012). Recent rhetorical studies in public understanding of science: Multiple purposes and strengths. Public Understanding of Science, 21(3), 386-400.

Curtis, R. (1994, August). Narrative form and normative force: Baconian story-telling in popular science. Social Studies of Science, 24(3), 419-461.

Elliott, J. (2002, March 18). The XXX-rated med school teacher. BBC News. Retrieved from http://news.bbc.co.uk. 
Fahnestock, J. (1986, July). Accommodating science: The rhetorical life of scientific facts. Written Communication, 3(3), 274-296.

Fleckenstein, K. S. (2001, Fall). Bodysigns: A biorhetoric for change. JAC, 21(4), 761-790.

Foucault, M. (1972). The archaeology of knowledge and the discourse on language. New York: Pantheon Books.

Fursich, E. \& Lester, E. P. (1996). Science journalism under scrutiny: A textual analysis of "Science Times." Critical Studies in Mass Communication, 13(1), 24-43.

Gross. A.G. (1994). The roles of rhetoric in public understanding of science. Public Understanding of Science, 3(1), 3-23.

Hennessy, R. (1993). Materialist feminism and the politics of discourse. London: Routledge.

Hyland, K. (2010). Constructing proximity: Relating to readers in popular and professional science. Journal of English for Academic Purposes, 9, 116-127.

Jasinski, J. (2001). Introduction: On defining rhetoric as an object of intellectual inquiry. Sourcebook on rhetoric (pp. xiii-xxxiv). Thousand Oaks, CA: Sage Publications.

Johnson, C. (2011, March 23). Future docs may have to pass new breast test. Seattle Times. Retrieved from http://o.seattletimes.nwsource.com.

Lynch, J. (2009). Articulating scientific practice: understanding Dean Hamer's 'Gay Gene' study as overlapping material, social and rhetorical registers. Quarterly Journal of Speech, 95(4), 435-56.

Morgan, R. (2008, Feb. 12). Building organs even the prudish can handle. The New York Times. Retrieved from http:// www.nytimes.com.

Murphy, M. (2004, Spring). Immodest witnessing: The epistemology of vaginal self-examination in the U.S. self-help movement. Feminist Studies, 20(1), 115-147. 
The National Institute of Biomedical Imaging and Bioengineering. (2012, June 22). Tenth anniversary program. Bethesda, MD. Retrieved from http://www.nibib.nih.gov.

Nelkin, D. (1995). Selling science: How the press covers science and technology. New York, NY: W. H. Freeman.

Neville, S. (2011, March 24). Medical students to get hands on experience with new fake breasts that can simulate tumours. The Daily Mail. Retrieved from http://www.dailymail.co.uk.

Pugh, C. (2012a, May 11). Honors and oaths. Howard University College of Medicine: Class of 2012 Graduation. Washington, D.C.

Pugh, C. (2012b, June 22). Use of sensors and simulation technology to quantify clinical palpation. The National Institute of Biomedical Imaging and Bioengineering 10th anniversary symposium: A decade of innovation for health. Bethesda, MD.

Rackl, Lori. (2007, May 1). She opened her doors- By discovering a better way to train med students, Dr. Carla Pugh isn't just a great black doctor. She's a great doctor. Period. Chicago Sun Times. Retrieved from http:// http://infoweb.newsbank.com.

Shachar, O. (2000). Spotlighting women scientists in the press: Tokenism in science journalism. Public Understanding of Science, 9(4), 347-358.

Shreve, J. (2002, March 18). Tech support for pelvic exams. Wired. Retrieved from http://www.wired.com.

Trice, D. T. (2010, June 28). Northwestern doctor takes hands on approach to breast exams. Chicago Tribune. Retrieved from http://www.chicagotribune.com.

Wilcox, S. A. (2003, September). Cultural context and the conventions of science journalism: Drama and contradiction in media coverage of biological ideas about sexuality. Critical Studies in Media Communication, 20(3): 225-247. 